\title{
INTRAVENOUS DIAZEPAM FOR PSYCHIATRIC REACTIONS FOLLOWING OPEN-HEART SURGERY*
}

\author{
ANDré McClish, M.D., F.R.C.P.(C), DANIEl ANDREw, M.D., AND \\ LÉon Tetreault, M.D., M.SC., F.C.P.C.†
}

PsYCHIATRIC REACTIONS following cardiac surgery have been reported by many authors during the past ten years. The incidence of these complications ranges from 3 to 46 per cent in closed-heart procedures, ${ }^{1-5}$ from 20 to 57 per cent in open-heart operations, ${ }^{6-12}$ and from 80 to 90 per cent in cases of valve replacement, ${ }^{13}$ according to published data.

The pathogenesis of these psychiatric disturbances following intracardiac surgery with cardiopulmonary bypass still remains obscure. ${ }^{8,11,12,14}$ The list of suspected factors includes the mental or cardiac status of the patient, the anaesthetic technique, the surgical procedure, and the extracorporeal circulation itself. However, Egerton ${ }^{8}$ and Kornfeld ${ }^{11}$ suggest the predominant cause to be the anxiety produced in the patient by the frightening and stressful atmosphere of the intensive care unit (I.C.U.).

The present study was undertaken to (1) determine the incidence and severity of psychiatric complications appearing after open-heart surgery, (2) discuss some of the factors involved in their pathogenesis, and (3) verify the efficacy of postoperative intravenous diazepam in their prevention and control. Diazepam is a psycholeptic drug of the benzodiazepine family. It possesses tranquillizing, muscle relaxant, and anticonvulsant properties which exceed more than five times those of chlordiazepoxide. ${ }^{15}$

\section{Materials and Methods}

\section{Definition}

For the sake of clarity and simplicity, the term "psychiatric reactions" employed in the present study refers to any postoperative behavioural disturbances not present before surgery. The clinical picture which generally appears after an initial lucid interval may include symptoms such as severe anxiety, nervous tension, disorientation, confusion, depression, hostility, and even hallucinations.

Although desirable, a complete preoperative and postoperative psychiatric evaluation of the cardiac patient by a psychiatrist is often considered a disturbing experience by the patient himself and by the physician. ${ }^{12,16}$ Therefore, in this

'Presented at the Annual Meeting of the Canadian Anaesthetists' Society, June 26-30, 1967. From the Research Center and the Department of Anaesthesiology, Institute of Cardiology, Laval Hospital, Quebec.

†Dr. McClish is Director of the Research Center, Laval Hospital, and Assistant Professor in the Department of Anaesthesiology, Laval University, Quebec. Dr. Andrew is Resident in Cardiology, Institute of Cardiology, Laval Hospital, Quebec. Dr. Tetreault is Assistant Professor in the Department of Pharmacology, University of Montreal, Montreal. 
series the patient's behaviour was assessed by the main investigator, who is an anaesthesiologist.

The preoperative interview, 24 to 48 hours prior to surgery, was mainly concemed with the patient's life history, his attitude towards his heart disease, and his anxiety in regard to anaesthesia, surgery, and the postoperative period. At this time, the anaesthetic procedure, the extracorporeal circulation, and the management in the I.C.U. were explained to the patient. Moreover, his chart was reviewed for pertinent clinical data. In the postoperative period, the patient was seen by the main investigator three to four times daily for at least a week. The comments by residents, physicians, and nurses about the clinical reactions of the patients were also taken into consideration. In a few cases, the psychiatric symptoms noted were verbally discussed with a psychiatrist.

\section{Patients}

The clinical investigation comprises 79 consecutive, unselected patients undergoing open-heart surgery with extracorporeal circulation at the Quebec Institute of Cardiology, from March 1964 to December 1965. They were operated upon by the same surgical team. The operations are listed on Table I. No deaths occurred during the six days following surgery.

TABLE I

\begin{tabular}{|c|c|c|}
\hline Open-heart procedures & $\begin{array}{l}\text { No. of } \\
\text { patients }\end{array}$ & Per cent \\
\hline \multicolumn{3}{|l|}{ Congenital diseases } \\
\hline \multicolumn{3}{|l|}{ Interatrial septal defect } \\
\hline O.S. (3 with p.hyp.) & 19 & \\
\hline O.P. & 2 & \\
\hline +P.S. (trilogy) & 4 & \\
\hline +A.P.V.R. & 3 & \\
\hline +M.S. (Lutembacher) & & \\
\hline \multicolumn{3}{|l|}{ Interventricular septal defect } \\
\hline simple & 5 & \\
\hline reoperation & 2 & \\
\hline +P.S. (tetralogy) & 8 & \\
\hline +P.S. and I.A.S.D. (pentalogy) & 1 & \\
\hline \multicolumn{3}{|l|}{ Pulmonary stenosis } \\
\hline $\begin{array}{l}\text { valv. } \\
\text { valv. and inf. }\end{array}$ & $\begin{array}{l}1 \\
5\end{array}$ & \\
\hline \multicolumn{3}{|l|}{ Aortic stenosis } \\
\hline $\begin{array}{l}\text { valv. } \\
\text { sous-valv. }\end{array}$ & $\begin{array}{l}3 \\
1\end{array}$ & \\
\hline Sub-total & 56 & 70.9 \\
\hline \multicolumn{3}{|l|}{ Acquired diseases } \\
\hline \multicolumn{3}{|l|}{ Mitral lesions } \\
\hline stenosis & 2 & \\
\hline insufficiency & 5 & \\
\hline disease & 4 & \\
\hline \multicolumn{3}{|l|}{ Aortic lesions } \\
\hline stenosis & 2 & \\
\hline insufficiency & 1 & \\
\hline disease & 6 & \\
\hline \multicolumn{3}{|l|}{ Mitral and aortic lesions } \\
\hline mitral and aortic diseases & 2 & \\
\hline aortic insufficiency and mitral disease & 1 & \\
\hline Sub-total & 23 & 29.1 \\
\hline Total & 79 & 100.0 \\
\hline
\end{tabular}


This series of 79 cases was divided into two groups: a control group of 37 subjects and a treatment group of 42 subjects. There were 14 children in the first group and 9 in the second. As these groups were studied consecutively and the patients in each one were not distributed at random, the observed results have only been subjected to a descriptive statistical analysis, since such a comparison cannot be tested by more rigorous methods such as the Student's $t$-test, the chi-square test, or the analysis of variance.

Table II shows that the two groups are equivalent with regard to sex, age, height, and type of cardiac lesion. Average weight is greater in the treatment group than in the control group, but the 95 per cent confidence limits overlap sufficiently to permit acceptance of the two groups as comparable. As seen in Table III, the degree of induced hypothermia and the bypass time are also comparable.

TABLE II

Pertinent Clinical Data (79 Patients)

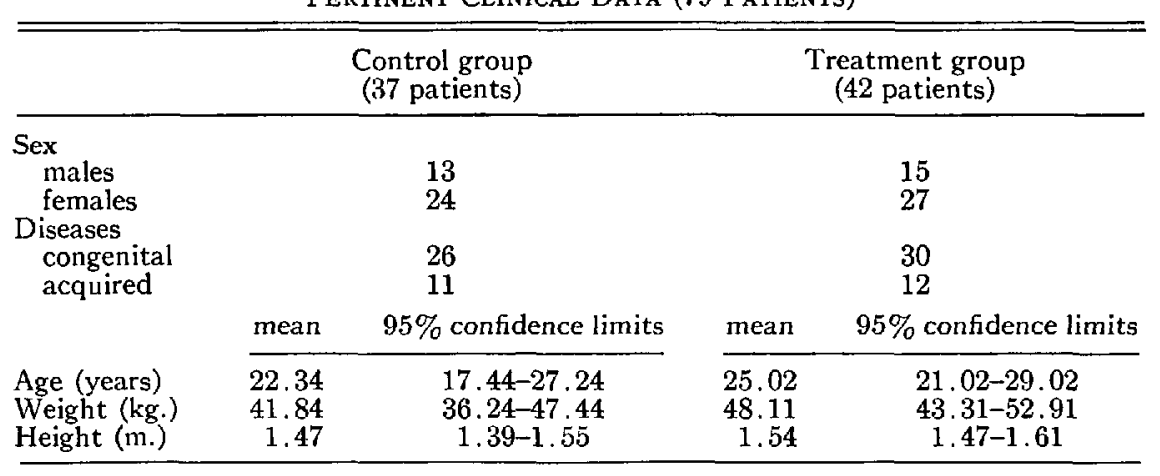

TABLE III

Pertinent Perfusion Data (79 Patients)

\begin{tabular}{lccccc}
\hline & \multicolumn{2}{c}{ Control group (37 patients) } & & \multicolumn{2}{c}{ Treatment group (42 patients) } \\
\cline { 2 - 3 } \cline { 6 - 7 } & mean & $95 \%$ confidence limits & & mean & $95 \%$ confidence limits \\
\hline Hypothermia $\left({ }^{\circ} \mathrm{C}\right)$ & 30.5 & $30.0-31.0$ & & 31.2 & $30.7-31.7$ \\
Bypass time (min.) & 59.5 & $42.3-76.7$ & & 77.0 & $\mathbf{6 1 . 4 - 9 2 . 6}$ \\
\hline
\end{tabular}

\section{Anaesthesia}

In all cases, the main investigator was responsible for the conduct of anaesthesia and cardiopulmonary bypass. The premedication consisted of meperidine $50 \mathrm{mg}$. and promethazine $25 \mathrm{mg}$. given intramuscularly an hour prior to anaesthesia. Vagolytic drugs were systemically omitted,

The patients were induced with a sleep dose of thiopentone followed by nitrous oxide, oxygen, and halothane. Intubation was performed with the aid of succinylcholine and topical anaesthesia with hexylcaine 5 per cent. Anaesthesia was maintained with the same gaseous mixture combined with moderate mechanical hyperventilation both before and after perfusion, and with moderate hypothermia, 
halothane, and succinylcholine during perfusion. ${ }^{17}$ Anaesthesia lasted on the average 7 hours and 22 minutes (from 4 hours and 15 minutes to 10 hours and 20 minutes) for the control group and 7 hours and 37 minutes (from 4 hours and 9 minutes to 11 hours and 13 minutes) for the treatment group. As presented in Table IV, the two groups were comparable as to the anaesthetic risk. ${ }^{18}$ There was no case in class I or II.

TABLE IV

Anaesthetic Risk ${ }^{1}$ (79 Patients)

\begin{tabular}{|c|c|c|c|c|c|c|}
\hline \multirow[b]{2}{*}{ Class } & \multicolumn{3}{|c|}{ Control group (37 patients) } & \multicolumn{3}{|c|}{ Treatment group ( 42 patients) } \\
\hline & $\begin{array}{l}\text { no. of } \\
\text { patients }\end{array}$ & per cent & $\begin{array}{l}95 \% \\
\text { confidence } \\
\text { limits }\end{array}$ & $\begin{array}{c}\text { no. of } \\
\text { patients }\end{array}$ & per cent & $\begin{array}{c}95 \% \\
\text { confidence } \\
\text { limits }\end{array}$ \\
\hline $\begin{array}{l}\text { I and II } \\
\text { III } \\
\text { IV }\end{array}$ & $\begin{array}{r}0 \\
11 \\
26\end{array}$ & $\begin{array}{c}0 \\
29.72 \\
70.27\end{array}$ & $\begin{array}{c}- \\
15.06-44.38 \\
55.61-84.93\end{array}$ & $\begin{array}{r}0 \\
9 \\
33\end{array}$ & $\begin{array}{c}0 \\
21.42 \\
78.57\end{array}$ & $\begin{array}{r}9 . \overline{0}-33.80 \\
66.19-90.95\end{array}$ \\
\hline Total & 37 & 100 & - & 42 & 100 & - \\
\hline
\end{tabular}

${ }^{1}$ According to criteria of the American Society of Anesthesiologists.

\section{Extracorporeal Circulation}

All perfusions were performed with haemodilution (Hb., $9.6 \mathrm{gm} . / 100 \mathrm{ml}$, and Hct., $27 \%)$, moderate hypothermia $\left(30.0^{\circ}\right.$ C. $)$ and high flow rates $\left(2.2 \mathrm{~L} . / \mathrm{m}^{2}\right.$ of body surface). These figures represent mean values. A bubble oxygenator modified and improved in our laboratory was used (Fig. 1). Its main characteristics include: a low bloodless priming volume (500 to $1500 \mathrm{ml}$. according to the patient's size), an efficient built-in heat exchanger, and a low-pressure coronary suction system. ${ }^{17}$

\section{Intensive Care Unit}

Our I.C.U. is staffed with graduate nurses having special training and experience in cardiopulmonary nursing. No important changes in the personnel occurred during this investigation. Medical supervision was assumed by the anaesthesiologist who is also trained in cardiovascular surgery. The patients stay an average of six days in the I.C.U.

The patients arrive in the I.C.U. already equipped with E.C.G. electrodes, thoracic drainage, saphenous-vena-caval catheter, radial artery needle, urinary catheter, gastric drainage, rectal telethermometer, and usually an endotracheal tube, unless they have a tracheostomy. All these components are connected to various observation, measurement, and treatment instruments (Fig. 2). Important parameters are under constant surveillance and are registered hourly on a special sheet. Arterial or venous blood samples are obtained three to four times daily for electrolytes, blood gas and acid-base measurements, etc.

\section{Postoperative Medication}

All adults of both groups received meperidine $50 \mathrm{mg}$. and diphenhydramine $20 \mathrm{mg}$. intramuscularly every three to four hours as well as other intravenous 


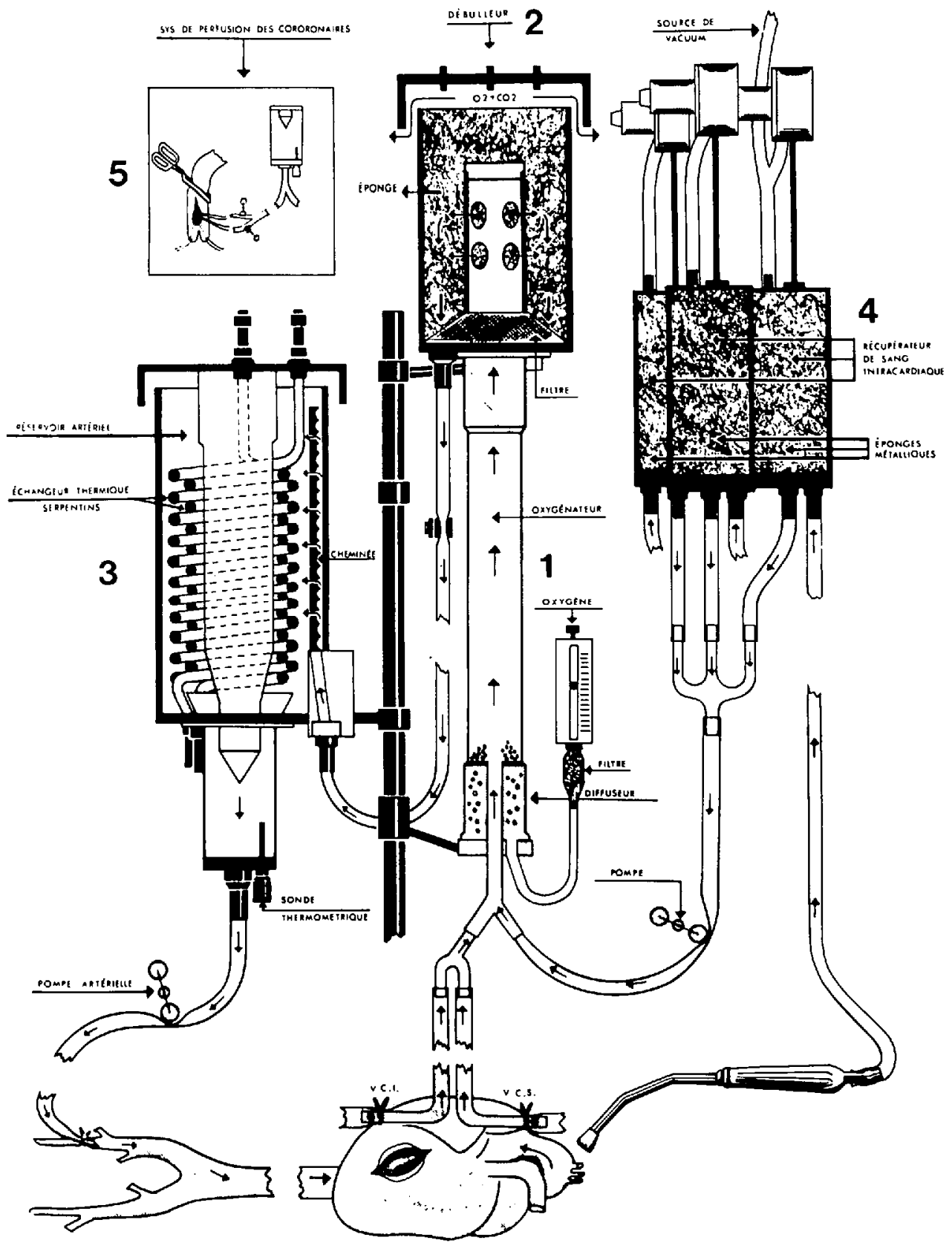

Figure 1. Schematic view of the heart-lung machine. 1. Bubble oxygenator and oxygen filter. 2. Debubbler and blood filter. 3. Arterial reservoir playing the role of a bubble trap and containing a twin coil heat exchanger. 4. Cardiotomy return system with three collection bottles in which a low negative pressure is exerted. 5 . Coronary perfusion set-up. The major advantages of this machine are a low bloodless priming volume $(500-1500 \mathrm{ml}$.) an efficient built-in heat exchanger with a temperature regulating valve, and a low-pressure coronary system. The extracorporeal circuit completely assembled is sterilized by gas with ethylene oxide. No more than ten minutes are required to set up the machine in the operating room. 


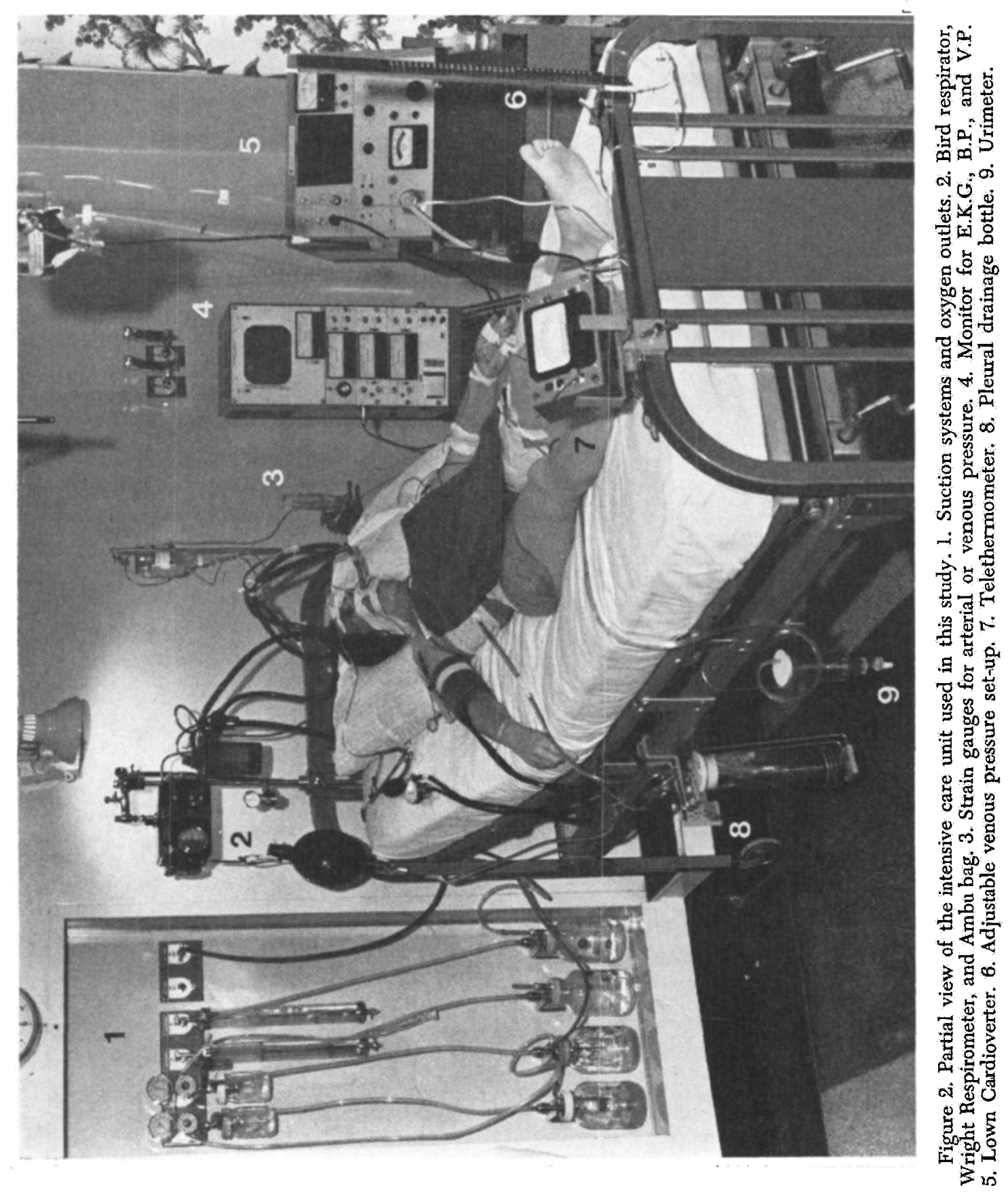




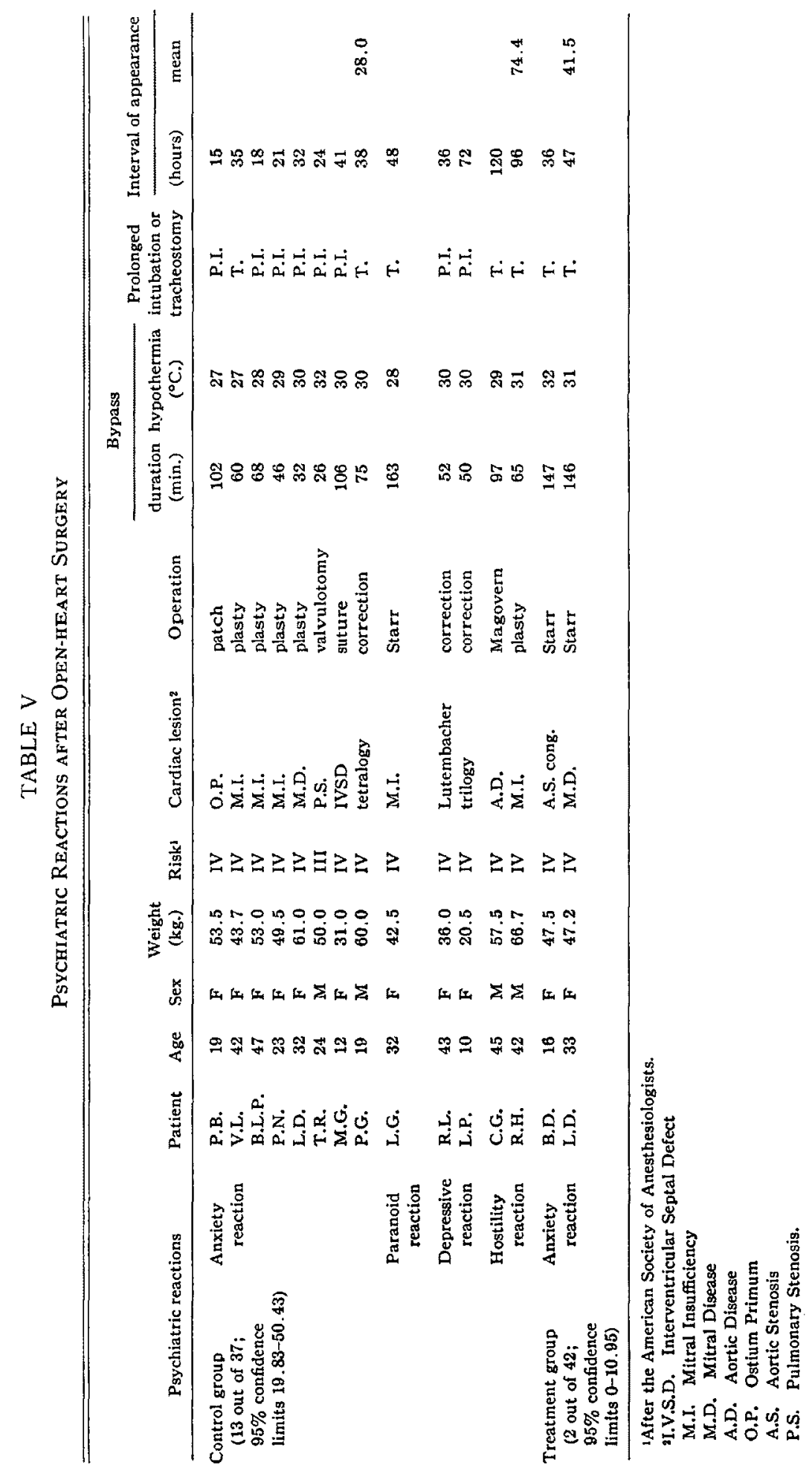


medications such as: digitalis, potassium chloride, antibiotics, dextran 40 . Children received appropriate doses of the same drugs. In addition, the treatment group was given diazepam 2.5 to $5.0 \mathrm{mg}$. by the intravenous route every four hours between the doses of sedatives.

\section{Results}

\section{Postoperative Psychiatric Complications}

Table $\mathrm{V}$, in addition to summarizing the pertinent clinical and perfusion data, indicates the occurrence, severity, and time of appearance of the postoperative psychiatric reactions encountered in both groups.

In the control group of 37 patients, $13(35.1 \%)$ presented psychiatric derangements following open-heart surgery. Eight (21.6\%) showed minor reactions characterized by severe anxiety and nervous tension, and five (13.5\%) had major disturbances characterized by paranoia reaction ( 1 case), depression reaction ( 2 cases), and hostility reaction ( 2 cases). Neither of the last 2 patients was alcoholic or febrile.

In the treatment group of 42 patients, two (4.7\%) developed minor postoperative emotional symptoms in the form of severe anxiety and nervous tension. Both were female and had previously undergone intracardiac surgery for the same valvular lesion. There was no instance of a major reaction in this group.

The following is a statistical breakdown of all patients exhibiting psychiatric reactions:

(a) Age. There were eleven adults and two children in the control group, and there were two adults and no children in the treatment group.

(b) Sex. There were four males and nine females in the control group in comparison to no males and two females in the treatment group.

(c) Anaesthetic risk. All patients were poor anaesthetic risks falling in class III ( 1 case) and in class IV ( 14 cases).

(d) Cardiac lesion. In the control group, there were five patients with congenital anomalies and eight with acquired lesions, of which seven were related to the mitral valve.

(e) Bypass time and degree of hypothermia. In the control group, the average bypass duration was shorter in cases of minor reactions (64.3 minutes) than in those of major reactions ( 85.4 minutes): There was almost no difference in the degree of hypothermia as between minor or major reactions. In the treatment group, where there were no major reactions, the bypass time averaged 146.5 minutes and the degree of hypothermia 31.5 minutes for the minor reactions.

(f) Respiratory assistance. All 15 subjects were subjected to mechanical ventilatory support for some time postoperatively: eight under prolonged intubation and five by means of tracheostomy in the control group, and two by tracheostomy in the treatment group.

(g) Postoperative lucid interval. In the control group, the lucid interval was, on the average, 28 hours for minor reactions and 74.4 hours for major reactions. In the treatment group, where there were only two minor reactions, the mean time of appearance was 41.5 hours. 


\section{Relation of Mechanical Ventilation to Postoperative Psychiatric Reactions}

Table VI gives for both groups the occurrence of postoperative emotional complications in connection with the use of mechanical ventilation. Of the 37 control patients, $23(62.1 \%)$ received postoperative mechanical ventilatory assistance, of whom the incidence of psychiatric reactions was 56.5 per cent ( 13 patients). Of the 42 treatment group patients, $39(92.0 \%)$ received ventilatory assistance, and the incidence of psychiatric reaction was 5.1 per cent ( 2 patients). All patients not given mechanical ventilatory support were nursed in an oxygen tent, and none presented psychiatric disturbances.

TABLE VI

Incidence of Postoperative Psychiatric Reactions Following Open-heart Surgery in Relation to Respiratory Assistance (79 Patients)

\begin{tabular}{|c|c|c|c|c|c|c|}
\hline \multirow[b]{3}{*}{ Mechanical ventilation } & \multicolumn{3}{|c|}{ Control group (37 patients) } & \multicolumn{3}{|c|}{ Treatment group (42 patients) } \\
\hline & \multirow{2}{*}{$\begin{array}{c}\text { Total } \\
\text { no. of } \\
\text { patients }\end{array}$} & \multicolumn{2}{|c|}{ Psychiatric reactions } & \multirow{2}{*}{$\begin{array}{c}\text { Total } \\
\text { no. of } \\
\text { patients }\end{array}$} & \multicolumn{2}{|c|}{ Psychiatric reactions } \\
\hline & & $\begin{array}{c}\text { no. of } \\
\text { patients }\end{array}$ & per cent & & $\begin{array}{l}\text { no. of } \\
\text { patients }\end{array}$ & per cent \\
\hline $\begin{array}{l}\text { Tracheostomy } \\
\text { Prolonged intubation }\end{array}$ & $\begin{array}{l}10 \\
13\end{array}$ & $\begin{array}{l}5 \\
8\end{array}$ & $\begin{array}{l}50.0 \\
61.5\end{array}$ & $\begin{array}{l}15 \\
24\end{array}$ & $\begin{array}{l}2 \\
0\end{array}$ & $\begin{array}{r}13.3 \\
0.0\end{array}$ \\
\hline Total & 23 & 13 & 56.5 & 39 & 2 & 5.1 \\
\hline
\end{tabular}

\section{Postoperative Intravenous Diazepam}

Minor and major psychiatric reactions encountered in the control group were controlled rapidly by the intravenous administration of diazepam, 15 to $30 \mathrm{mg}$. daily in fractional doses. On the other hand, the two minor reactions observed in the treatment group and not prevented by the postoperative use of prophylactic intravenous diazepam were easily treated by chlorpromazine $25 \mathrm{mg}$. intramuscularly four times a day.

\section{Discussion}

Although it is difficult to draw valid conclusions from comparisons between two consecutive groups, certain consistent observations have valuable significance. It is useful to remember that anaesthesia, extracorporeal circulation, intracardiac surgery, and postoperative management were conducted by the same medical and surgical team, using the same techniques and equipment and dealing with comparable clinical material.

\section{Occurrence of Postoperative Psychiatric Complications}

In our control group, there was a 35.1 per cent incidence of psychiatric reactions after open-heart surgery, the 95 per cent confidence interval ranging from 19.83 to 50.43 per cent. These figures are in keeping with those reported by Kornfeld (38\%), ${ }^{11}$ Egerton (41.6\%), ${ }^{8}$ Silverstein (33\%), ${ }^{6}$ and Burgess (25.4 $27.8 \%),{ }^{12}$ but they are lower than those published by Blachly (57\%). ${ }^{7}$ 


\section{Pathogenesis}

The nature of psychiatric complications following intracardiac surgery still remains obscure due to numerous factors (organic, biochemical, and psychological) involved in their production. Only the major contributing factors in this respect will deserve further consideration.

Age. Emotional disturbances are rare complications in children following openheart surgery. There was one case reported by Egerton and Kay ${ }^{8}$ and none observed by Kornfeld..$^{11}$ It is the view of Nagy, ${ }^{19}$ Kornfeld, ${ }^{11}$ and Hazan ${ }^{14}$ that the nature of anxiety encountered in children is totally different from that noted in adults. As opposed to adults, the concern of the child may be more with pain and its relief than with the problems of life and death. It seems, moreover, that the brain of a child does not achieve neurophysiological maturity until approximately the age of 13. In our control group, two young girls 10 and 12 years old developed postoperative psychiatric disturbances of a minor type.

Sex. Blachly and Starr ${ }^{7}$ reported a higher incidence of psychiatric reactions in males $(31 \%)$ than in females (17\%). On the contrary, the sex of the patients was not found to be a significant factor in the Kornfeld's study. ${ }^{11}$ In our series, psychiatric reactions were observed in 9 females out of 24 (37.5\%) and in 4 males out of $13(30.7 \%)$ in the control group. Although there was a slight preponderance of females, the number of subjects was too small to indicate any trend.

Type of cardiac lesion. The incidence of psychiatric reactions after intracardiac surgery is higher for acquired than for congenital lesions, as shown in Table VII. ${ }^{8,11,12}$ This is quite obvious in the Burgess study ${ }^{12}$ and in our series. It may be accounted for by the fact that patients with acquired diseases are usually sicker than those with congenital anomalies, especially in the present study, where all the subjects were poor-risk patients falling in class III or IV.

TABLE VII

Incidence of Psychiatric Reactions after Open-heart Surgery in Relation to the Type of Lesions Corrected (ACCORding to Published Data)

\begin{tabular}{lcl}
\hline & Congenital diseases & Acquired diseases \\
\hline $\begin{array}{l}\text { Egerton and Kay } \\
\text { no. of patients }\end{array}$ & $4 / 10$ & \\
$\quad$ per cent & 40.0 & $21 / 50$ \\
Kornfeld & & 42.0 \\
$\quad$ no. of patients & $6 / 20$ & $21 / 49$ \\
$\quad \begin{array}{l}\text { per cent } \\
\text { Burgess }\end{array}$ & 30.0 & 43.8 \\
no. of patients & $5 / 100$ & $59 / 152$ \\
per cent & 5.0 & 38.8 \\
Present study & & $8 / 11$ \\
no. of patients & $5 / 26$ & 72.7 \\
per cent & 19.2 & \\
\hline
\end{tabular}

There is a tendency, on the other hand, for postoperative psychiatric disorders to be more common in patients with rheumatic mitral valve disease than in those with congenital lesions as reported by Egerton and Kay ${ }^{8}$ as well as by Bolton and Bailey. ${ }^{3}$ No significant difference was observed in the Kornfeld's series. ${ }^{11}$ In our 
control group, 7 of the 13 patients who experienced psychiatric reactions had rheumatic mitral valve disease. This represents 63.8 per cent of all the single mitral valve lesions corrected in the present study. Bruetsch and Williams, ${ }^{20}$ reporting on cerebral sequelae in rheumatic heart disease, witnessed a higher incidence of cerebral pathology in cases implicating the mitral valve.

Anaesthetic risk. A relation exists between the severity of the anaesthetic risk of the patient's physical incapacity and the frequency of psychiatric disorders after intracardiac surgery as noted by Kornfeld ${ }^{11}$ and Blachly. ${ }^{7}$ This was also the case in our series; the 15 patients who presented psychiatric reactions were either in class III ( 1 out of 11 ), or in class IV (12 out of 26 ) for the control group and in class IV ( 2 out of 23 ) for the treatment group, according to the criteria of the American Society of Anesthesiologists. In contrast with the studies of Kornfeld and Blachly, there were no patients in classes I and II in our study.

Extracorporeal circulation. Cardiopulmonary bypass has often been associated with biological disturbances and cerebral complications. For these reasons it has been frequently incriminated as responsible for postperfusion psychiatric disorders. ${ }^{6,0,14,21,22}$

The same physiological controls having been carried out in all the patients in this study, no serious derangements of parameters such as acid-base equilibrium, electrolytes, water balance, blood volume, oxygen saturation, etc. have been found in the 15 patients who manifested postoperative emotional disorders. Retrospective analysis of the haemodynamic, electroencephalographic, and biochemical data in these same subjects evidenced no signs of cerebral involvement caused by anoxia, acidosis, venous congestion, or hypotension. None of these patients exhibited any clinical findings of neurological deficit.

It is useful to emphasize that in all our patients extracorporeal circulation was conducted using haemodilution, moderate hypothermia, and basal flow rates. This technique affords good protection against cerebral hypoxia and provides better tissue perfusion. ${ }^{23}$

In agreement with Egerton and $\mathrm{Kay}_{,}{ }^{8}$ we found no reason to believe that the type of oxygenator used was a causative factor in the formation of psychiatric disturbances following intracardiac surgery. The incidence of such complications was 38 per cent in the series of Kornfeld ${ }^{11}$ using a disk oxygenator; it was 40 per cent in the report of Egerton and Kay, ${ }^{8}$ and 25.4 to 27.8 per cent in that of Burgess, ${ }^{12}$ using a screen oxygenator. In the present study where a modified bubble oxygenator was employed, the occurrence of psychiatric reactions was 35.1 per cent in the control group. Therefore, it is suggested that the principle of blood oxygenation seems to be more concerned with the aetiology of these complications than the type of oxygenator used.

Moreover, no correlation could be established in our series between the bypass time, the duration of anaesthesia, or the degree of hypothermia, and the occurrence of emotional reactions after open-heart surgery as already reported by Kornfeld. ${ }^{11}$

Mechanical ventilation. Mechanical ventilatory support by means of prolonged intubation or tracheostomy is often indicated after open-heart surgery, as demonstrated by Dammann. ${ }^{24}$ Such a therapeutic measure may be suspected to 
play a part in the development of psychiatric complications. In fact, in the Burgess study, ${ }^{12} 50$ per cent of the patients with tracheostomy and assisted ventilation had severe postoperative psychiatric reactions. This was also mentioned in two other reports ${ }^{6,8}$ and was not observed in a third one. ${ }^{11}$ In the present series, 13 of the 23 patients (56.5\%) in the control group and 2 of the 39 subjects $(5.1 \%)$ in the treatment group, who were under respirator support, experienced serious psychiatric disturbances. When prolonged intubation was used, the incidence was 61.5 per cent ( 8 out of 13) in the control group and nil in the treatment group; the occurrence was 50 per cent (5 out of 10) in the control group and 13.3 per cent ( 2 out of 15 ) in the treatment group when a tracheostomy was performed. In contrast, no psychiatric derangements were noted in the remaining patients of both groups who were nursed in an oxygen tent.

In view of these results, the physiological and psychological effects of mechanical ventilation by means of prolonged intubation or tracheostomy must be taken into consideration. Recently Blachly and Kloster, ${ }^{25,26}$ reporting on the relation of cardiac output and blood volume studies to postcardiotomy delirium, presented evidence that psychiatric complications after intracardiac surgery were possibly related to changes in cardiac output. Thus, hallucinations were mainly associated with high cardiac output states, while brain syndrome was frequently seen in patients with either low cardiac output or cerebral embolism, or in those under mechanical ventilation, these factors presumably producing decreased cerebral blood flow. On the contrary, none of our 15 patients who presented postoperative psychiatric disorders had clinical signs of serious variations in cardiac output or blood volume, nor did they show evidence of severe cardiac failure or cerebral embolism.

It is well known that hypocapnia secondary to mechanical overventilation may decrease cerebral blood flow. However, it has not been demonstrated clinically that moderate hyperventilation $\left(\mathrm{P}_{\mathrm{CO}_{2}}>30 \mathrm{~mm}\right.$. $\left.\mathrm{Hg}\right)$ may seriously impair cerebral function, except perhaps in cases of low cardiac output or cerebrovascular disease. ${ }^{27-31}$

It is apparent, on the other hand, that the psychological factors related to prolonged intubation or tracheostomy may be more important than the effects of hyperventilation on cerebral circulation in setting the stage for psychiatric reactions. Failure to explain to the patient the nature of his disease and the reasons for this therapeutic measure, inability to communicate with nurses, doctors, relatives (especially when the patient is intubated or when his dominant hand is not free to write), feeling of suffocation during tracheobronchial aspiration or change of the tracheostomy tube, fear of mechanical failure of the respirator as well as accidental disconnection or kinking of the tubes, lack of sleep due to constant nursing or respiratory care-all are factors which contribute to patient anxiety. These psychological implications already suggest the use of psycholeptic drugs in patients under respirator support.

Intensive Care Unit (I.C.U.). The stressful atmosphere of the I.C.U., more than anthing else, seems implicated in the genesis of psychiatric disorders after openheart surgery. ${ }^{8,11}$ In our I.C.U., especially designed to care adequately for 
patients returning from intracardiac surgery, almost all vital functions are taken over with the help of machines (respirator, pacemaker), therapeutic measures (intravenous fluid, drugs, prolonged intubation or tracheostomy), and various monitoring devices (for E.C.G., V.P., B.P., rectal temperature, urinary output, etc.). Although these procedures are life-saving, they are frequently perceived by the anxious patient as indices of deteriorating clinical condition and impending death.

In such a strange environment, the patient in all probability experiences both sensory saturation and motor deprivation. This paradoxical situation can only lead to severe anxiety where the threat of death is present. Factors capable of inducing sensory overstimulation or emotional irritability in the I.C.U. are deprivation of sleep, pain from thoracotomy, movements, multiple needle punctures, annoying sounds from respirators, oxygen tent, and cardiac monitors, as well as noise from nurses, residents, etc., difficulty in communication by talking or writing (intubation, tracheostomy, immobilization of the dominant hand), sometimes unsympathetic or thoughtless remarks by the medical and nursing staff, the troubling spectacle of newly arriving and dying patients, agitation and sudden activity of the personnel when emergencies arise, distress of neighbouring patients, etc.

The motor deprivation comes mainly from the relative immobility of the patient constrained by pain, urinary catheter, chest tube, wires, and intravenous fluid tubing so that the patient's field of vision is frequently restricted to the ceiling.

Taken together, all these factors are more than sufficient to produce psychiatric reactions in patients whose emotional balance is often precarious, thereby endangering the success of the entire surgical procedure.

\section{Management}

Egerton and $\mathrm{Kay}^{8}$ suggest the administration of a good nocturnal sedation and the avoidance of dehydration and electrolyte imbalance as prophylactic measures to decrease emotional disorders after open-heart surgery. Blachly and Starr, ${ }^{7}$ as well as Kloster, ${ }^{13}$ find the phenothiazines helpful to sedate anxious patients. Kornfeld ${ }^{11}$ reports the clinical impression that he succeeded in decreasing the incidence and severity of postoperative psychiatric complications in his patients by not disturbing them during their sleep, by muffling the sounds of the machines in the I.C.U., and by allowing them to listen to the radio. Pre- and postoperative psychological measures have also been recommended by many authors. ${ }^{10,12,32}$ We used therapeutic measures similar to those of Egerton, ${ }^{8}$ Kornfeld, ${ }^{11}$ and others in our I.C.U. Despite this, the incidence of psychiatric disturbances was 35.1 per cent in our control group.

It is well documented that psychological stresses in surgical patients are usually accompanied by an increased production of endogenous physiological amines (epinephrine, norepinephrine, etc.) which may be supplemented or stimulated by an exogenous supply of the same amines and related substances resulting from the use of extracorporeal circulation. ${ }^{14}$ Recent advances in neurophysiology and psychopharmacology have shown that any imbalance in these 
amines may be manifested in heightened or depressed emotions with associated changes in behaviour, and researchers have stressed the usefulness of psycholeptic drugs, in their management. ${ }^{14,33,34}$

\section{Diazepam}

Diazepam, like chlordiazepoxide, is a psychotherapeutic agent of the benzodiazepine family. This relatively new chemical class of compounds shows unique taming effects in animals and anti-anxiety effects in humans. ${ }^{15}$ Although the mode of action of the benzodiazepines is not known, electrophysiological studies suggest that they probably act by depressing the limbic system.

Diazepam is more potent than chlordiazepoxide in its anti-anxiety, muscle relaxant, and anticonvulsant properties. Free of analgesic and anti-emetic action, when given intravenously it possesses good sedative and hypnotic activity without adverse effects on respiration, circulation, and the autonomic nervous system. ${ }^{35}$ Unlike the phenothiazines, it does not produce tachycardia, hypotension, or extrapyramidal side-effects.

Clinical experience with diazepam has been limited mostly to the treatment of psychoneuroses in which the clinical picture is characterized by paranoid and affective features dominated by anxiety and depression. ${ }^{36-40}$ It has also proven useful in treating neuromuscular or musculo-skeletal disorders. ${ }^{41}$ In anaesthesiology, diazepam has been demonstrated to be particularly advantageous as a preanaesthetic medication as well as an induction agent for general anaesthesia..$^{35}$

In this study, intravenous diazepam has been effective in terminating and preventing psychiatric reactions following open-heart surgery. Moreover, when the usual postoperative analgesic medication was completed by diazepam sedation, as was the case in the treatment group, the patients lay in their beds calm, relaxed, co-operative, conversant, and slightly drowsy. Nursing care and treatment procedures were carried out with no difficulties. Prolonged intubation with respiratory assistance when indicated was surprisingly well tolerated for 48 to 72 hours without bucking, agitation or attempts to remove the tube. There was no need for muscle relaxants, large doses of narcotics, or nitrous oxide inhalation. Although a synergistic action is possible between diazepam and other sedative drugs, no evidence of respiratory depression was noted in patients nursed in an oxygen tent when intravenous diazepam was administered between the doses of narcotics. Insomnia was no longer a problem. Above all, intravenous diazepam produced very good amnesia, so that the patients seldom recalled their stay in the I.C.U.

\section{Summary and Conclusions}

The present study, based on a series of 79 consecutive unselected patients undergoing open-heart surgery with extracorporeal circulation at the Quebec Institute of Cardiology, was undertaken to determine the occurrence and severity of postoperative psychiatric complications, to discuss some of the factors involved in their pathogenesis, and to test the effectiveness of intravenous diazepam in their prevention and control.

The 79 patients were divided into two groups: a control group of 37 subjects 
and a treatment group of 42 subjects. In the treatment group only, the usual postoperative analgesic medication was completed by intravenous doses of diazepam 2.5 to $5 \mathrm{mg}$. six times a day given between the doses of narcotics. Both groups were comparable as to the age, sex, height, weight, anaesthetic risk, degree of hypothermia, bypass time, duration of anaesthesia, and type of cardiac lesion.

Our results are as follows: (a) The incidence of psychiatric complications was 35.1 per cent ( 13 cases) in the control group and 4.7 per cent (two cases) in the treatment group. $(b)$ There were eight minor and five major reactions in the control group in comparison to two minor and no major disturbances in the treatment group. (c) Postoperative mechanical ventilatory support was carried out more frequently in the treatment group (92.0\%) than in the control group (62.1\%), yet the occurrence of psychiatric reactions was 5.1 per cent in the treatment group as compared to 56.5 per cent in the control group.

It is concluded that the postoperative use of intravenous diazepam as an adjunct to the usual analgesic medication has markedly reduced the incidence and severity of psychiatric complications after intracardiac surgery with cardiopulmonary bypass. In the treatment group, the use of intravenous diazepam has resulted in better patient behaviour, and an improved patient-nurse and patientdoctor relationship. Because of the amnesic properties of this drug, the I.C.U. is no longer described as a "torture chamber" to prospective patients.

\section{RÉSUMÉ}

La présente étude, basée sur une série de 79 malades consécutifs, non sélectionnés, opérés à cœur ouvert à l'Institut de Cardiologie de Québec, fut entreprise dans le but de déterminer la fréquence et la gravité des complications psychiatriques postopératoires, de passer en revue les principaux facteurs susceptibles d'être impliqués dans leur pathogénie et de vérifier enfin l'efficacité du diazepam intraveineux dans leur traitement préventif et curatif.

Ces 79 malades furent partagés en deux groupes: un groupe témoin de 37 sujets et un groupe traité de 42 sujets. Dans le groupe traité seulement, la médication analgésique postopératoire fut complétée par du diazepam intraveineux; lequel fut administré dans l'intervalle des calmants habituels, à la dose de 2.5 à $5 \mathrm{mg}$. toutes les quatre heures. Les deux groupes étaient comparables quant à l'âge, au sexe, à la taille, au poids, au risque anesthésique, au degré d'hypothermie, au temps de perfusion, à la durée de l'anesthésie et au type de lésion cardiaque.

Les résultats de cette étude peuvent se résumer ainsi: (a) La fréquence des complications psychiatriques fut de 35.1 pour cent (13 cas) dans le groupe témoin, et de 4.7 pour cent (deux cas) dans le groupe traité. (b) Il est survenu huit réactions mineures et cinq réactions majeures dans le groupe témoin, contre deux réactions mineures et aucune réaction majeure dans le groupe traité. (c) Même si la ventilation mécanique fut utilisée plus fréquemment dans le groupe traité $(92.0 \%)$ que dans le groupe témoin $(62.1 \%)$, la fréquence des réactions psychiatriques fut moins élevée dans le premier groupe (5.1\%), que dans le second (56.5\%).

Les auteurs en concluent que l'emploi postopératoire du diazepam intraveineux 
comme adjuvant de la médication analgésique habituelle a permis de diminuer de façon marquée, la fréquence et la sévérité des complications psychiatriques après chirurgie cardiaque sous circulation extracorporelle. De plus, l'utilisation du diazepam intraveineux dans le groupe traité a eu pour effet d'améliorer le comportement psychique des opérés, tout en favorisant les relations patientinfirmières, et patient-médecins. A cause des propriétés amnésiques de cette drogue, la salle de soins intensifs n'est plus décrite aux futurs opérés comme une "chambre de torture".

\section{ACKNOWLEDGMENTS}

We wish to thank Drs. M. Beaulieu, J. P. Després, and J. A. Gravel for their co-operation in this study. Intravenous diazepam was supplied through the courtesy of Hoffmann-La Roche Company (Montreal).

\section{Drugs}

Generic and trade names of the drugs mentioned in this report are as follows:

Chlordiazepoxide Librium
Diazepam Valium
Diphenhydramine Benadryl
Halothane Fluothane
Hexylcaine Cyclaine
Meperidine Demerol
Promethazine Phenergan
Succinylcholine Anectine
Thiopental Pentothal

\section{REFERENCES}

1. Fox, H. M.; Rrzzo, N. D.; \& GrFford, S. Psychological Observations of Patients Undergoing Mitral Surgery: Study of Stress. Psychosomat. Med. 16: 186 (1954).

2. Bliss, E. L.; Rumel, W. R.; \& Branch, C. H. H. Psychiatric Complications of Mitral Surgery: Report of Death after Electroshock Therapy. Arch. Neurol. Psychol. 74: 249 (1955).

3. Bolton, H. E. \& BaIlex, C. P. Psychosomatic Aspects of Cardiovascular Surgery. In Psychosomatic Aspects of Surgery, edited by A. J. Cantor and A. N. Foxe. New York: Grune and Stratton (1956).

4. Mexer, B. C.; Blacher, R. S.; \& Brown, F. A Clinical Study of Psychiatric and Psychological Aspects of Mitral Surgery. Psychosomat. Med. 23: 194 ( 1961).

5. Knox, S. J. Severe Psychiatric Disturbances in Post-Operative Period: Five-Year Survey of Belfast Hospitals. J. Ment. Sc. 107: 1078 (1961).

6. Silverstein, A. \& Kruger, H. P. Neurologic Complications of Cardiac Surgery. Arch. Neurol. 3: 601 (1960).

7. Brachly, P. H. \& Starr, A. Post-Cardiotoney Delirium. Am. J. Psychiat. 121: 371 (1964).

8. Egerton, N. \& Kax, J. H. Psychological Disturbances Associated with Open-Heart Surgery. Brit. J. Psychiat. 110: 433 (1964).

9. Gilman, S. Cerebral Disorders After Open-Heart Operations. New England J. Med. 272 : 489 (1965).

10. Abram, H. S. Adaptation to Open-Heart Surgery: A Psychiatric Study of Response to the Threat of Death. Am. J. Psychiat. 122: 659 (1965).

11. Kornfeld, D. S.; Znmberg, S.; \& Malm, J. R. Psychiatric Complications of Open-Heart Surgery. New England J. Med. 273: 287 ( 1965 ). 
12. Burgess, G. N.; KirKlin, J. W.; \& Steinhilber, R. N. Some Psychiatric Aspects of Intracardiac Surgery, Mayo Clin. Proc. 42: 1 (1967).

13. Kloster, F. E.; Bristow, J. P.; \& Griswold, H. E. Medical Problems in Mitral and Multiple Valve Replacement. Progr. Cardiov. Dis. 7: 504 (1965).

14. HazaN, S. J. Psychiatric Complications Following Cardiac Surgery. J. Thoracic. Cardiov. Surg. 51: 307 (1966).

15. Randall, L. O.; Heise, G. A.; Schallex, W.; Bagdon, R. E.; Banziger, R.; Bonis, A.; MoE, R. A.; \& Abrams, W. B. Pharmacological and Clinical Studies on Valium, a New Psychotherapeutic Agent of the Benzodiazepine Class. Curr. Therap. Res. 3: 405 (1961).

16. Hacket, T. P. Discussion Following the Article of ABram, H. S. Adaptation to OpenHeart Surgery: A Psychiatric Study of Response to the Threat of Death. Am. J. Psychiat. 122: 659 (1965).

17. McClish, André; Despres, J. P.; Beaulieu, M.; \& Dechene, J. P. L'AnesthésisteRéanimateur et la circulation extracorporelle. Laval Med. 36: 583 (1965).

18. SAKLAD, M. Grading of Patients for Surgical Procedures. Anesthesiology. 2: 281 (1941).

19. Nacy, M. Child's Theories Concerning Death. J. Genet. Psychol. 73: 3 (1948).

20. Bruetsch, W. L. \& Williams, C. L. Embolic Cerebral Sequelae in Rheumatic Mitral Stenosis Precipitating Senile Mental Deterioration. Am. J. Psychiat. 116: 364 (1959).

21. Lindberg, D. A.; Lucas, F. V.; Sheagren, J.; \& Malm, J. R. Silicone Embolization during Clinical and Experimental Heart Surgery Employing Bubble Oxygenator. Am. J. Path. 39: 129 (1961).

22. ZAKS, M. S. Disturbances in Physiologic Functions and Neuropsychiatric Complications in Heart Surgery. In Luisada, A. A. Cardiology: An Encyclopedia of the Cardiovascular System, 4 vols. Vol. 3, New York: McGraw-Hill (1958), pp. 162-171.

23. Paton, B. C. \& Rosekrantz, J. Non-Hemic Priming Fluids for Extra-Corporeal Circulation. Dis. Chest. 48: 311 (1965).

24. DammanN, J. F. The Importance of Controlled Ventilation Following Open-Heart Surgery. Int. Anesth. Clin. 2: 55 ( 1963).

25. Blackly, P. H. \& Kloster, F. E. Relation of Cardiac Output to Post-Cardiotomy Delirium. J. Thorac. Cardiov. Surg. 52: 422 (1966).

26. Kloster, F. E.; Bristow, J. D.; Starr, A.; McCond, C. W.; \& Griswold, H. E. Serial Cardiac Output and Blood Volume Studies Following Cardiac Valve Replacement. Circulation. 33: 528 (1966).

27. Safar, P. \& Kunkel, H. G. Prolonged Artificial Ventilation. Clin. Anesth. 1: 94 (1965).

28. Rosomoff, H. L. \& Safard, P. Management of the Comatose Patient. Clin. Anesth. 1: 244 (1965).

29. Wylie, W. D. \& Churchill-Davmson, H. C. The Cerebral Circulation and Brain Metabolism. In A Practice of Anaesthesia. London: Lloyd-Luke (1966).

30. Evans, F. T. \& Gray, T. C. The Clinical Application of Relaxant Drugs. In General Anaesthesia. London: Butterworths (1965).

31. Whitwan, S. G.; Boetrner, R. B.; Grlger, A. P.; \& Littell, A. Hyperventilation, Brain Damage and Flicker. Brit. J. Anaesth. 38: 846 (1966).

32. Harrison, T. R. \& Reeves, T. J. The Psychologic Management of Patients with Cardiac Disease. Am. Heart. J. 70: 136 (1965).

33. Remmen, E.; Cohen, S.; Drtman, K.; \& Frantz, J. R. Psychochemotherapy. In The Physician's Manual. Los Angeles: Western Medical Publications, (1962).

34. Schallek, W. \& Zabransky, F. Effects of Psychotropic Drugs on Pressor Responses to Central and Peripheral Stimulation in the Cat. Arch. Internat. Pharmacodyn. 161: 126 (1966).

35. MCClish, ANdré. Diazepam as an Intravenous Induction Agent for General Anaesthesia. Canad. Anaesth. Soc. J. 13: 561 (1966).

36. Coulard, J. Clinical Experience with Diazepam in Neuroses. J. Neuropsychiat. 3: suppl. I: 157 (1962).

37. Difrancesco, A. Diazepam, a New Tranquilizer. Am. J. Psychiat. 119: 989 (1963).

38. Procton, R. C. The Impioved Management of Incapacitating Anxiety States. J. Neuropsychiat. 3, suppl. 1: 151 (1962).

39. Boitelle, G.; Boitelle-Lentulo, C.; Cophicnon, J.; Blotulkas, G.; \& Thomas, I. Indications du R.05-2807 dans les états d'excitation et d'anxiété. Ann. médico-psychol. 121: 83 (1963).

40. Feldman, P. E. An Analysis of the Efficacy of Diazepam. J. Neuropsychiat. 3, suppl. 1: $62(1962)$.

41. Katz, R. A.; Aldes, J. H.; \& Rector, M. A New Drug Approach to Muscle Relaxation. J. Neuropsychiat. 3, suppl. 1: 91 (1962). 